\title{
O uso do Facebook como ferramenta para o compartilhamento de atividades pedagógicas: uma experiência em uma escola pública de educação infantil
}

\section{Facebook as a tool for knowledge sharing: an experience in a Brazilian early chilhood education public school}

\author{
Priscila Marin Bernardi ${ }^{1}$, Scheila de Avila e Silva ${ }^{1}$ \\ ${ }^{1}$ Universidade de Caxias do Sul - UCS, Vacaria, Brasil
}

Autor para correspondência/Mail to: Scheila de Avila e Silva sasilva6@ucs.br

Recebido/Submitted: 13 Out. 2015; Aceito/Approved: 30 Nov. 2015

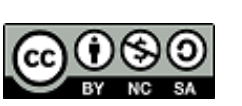
Copyright (c) 2015 Marin Bernardi \& de Avila e Silva. Todo o conteúdo da Revista (incluindo-se instruções, política editorial e modelos) está
sob uma licença Creative Commons Atribuição-NãoComercial-Compartilhalgual 3.0 Não Adaptada. Ao serem publicados por esta Revista, os ar-
tigos são de livre uso em ambientes educacionais, de pesquisa e não comerciais, com atribuição de autoria obrigatória. Mais informações em
http://ojs.c3sl.ufpr.br/ojs2/index.php/atoz/about/submissions\#copyrightNotice.

\begin{abstract}
Resumo
Introdução: A disseminação e incorporação de mídias sociais no cotidiano levanta a questão de seu uso como ferramentas de apoio pedagógico. Deste modo, o presente trabalho descreve uma reflexão sobre o tema tendo como base uma experiência de utilização da mídia social Facebook como mecanismo de compartilhamento de atividades pedagógicas em uma escola pública de educação infantil. Este trabalho teve como objetivo investigar o significado do compartilhamento de informações nos indivíduos desta comunidade escolar.

Método: Utilizou-se análise qualitativa dos dados derivados de entrevistas e de relatos escritos pelos participantes.

Resultados: O projeto envolveu todos os integrantes da comunidade escolar: professores, funcionários e responsáveis pelos alunos e, após um ano de utilização da mídia social, foram realizadas 26 postagens na página da escola e 31 no grupo secreto, aproximadamente. Os participantes internos da escola relataram benefício no fluxo de informações, enquanto que os membros externos da comunidade escolar descrevem os benefícios de acompanhar a rotina das crianças.

Conclusão: Os relatos apontam para a aceitação da ferramenta tanto pelos colaboradores da instituição, quanto pela comunidade externa. Assim, percebe-se que há uma potencialidade de se aprimorar a prática docente, além dos benefícios da utilização desta mídia social na comunicação da escola com a comunidade externa.
\end{abstract}

Palavras-chave: Compartilhamento de Conhecimento; Mídias de Redes Sociais; Práticas em educação

\begin{abstract}
Introduction: The dissemination and incorporation of social media in the daily life raises the question about their use as a supportive tool in the educational context. Bearing this in mind this paper describes a reflection about this subject starting from an experience of the use of Facebook - a Social Media Network - as a tool for sharing pedagogical activities in a public school of early childhood education.

Method: A qualitative analysis was carried out in order to investigate the individual or group opinion about knowledge sharing issue. The data were obtained by interviews and reports written by the participants.

Results: After a year of use, 26 messages were posted in the school page and 31 posts in the secret group, roughly. The posts involved all members of the school community: teachers, staff and student's parents and relatives. Teachers and employees reported that experience improved the communication flow of the school. The parents and relatives describe how the page help them to follow the routine of school and the children development. Conclusion: The reports of all participants of the present case study indicate an acceptance of the Facebook as an institutional informational tool. The sharing of knowledge, by using digital social media, can be an important tool in the improvement of teacher practice and communication with the external community.
\end{abstract}

Keywords: Knowledge sharing; Web Social Networks; Educational practices

\section{INTRODUÇÃO}

As tecnologias da informação e comunicação (TIC) permitem o armazenamento, a rápida difusão e elaboração de informações, atuando como um catalisador de mudanças, uma vez que criam novas necessidades e alteram velhos e sólidos paradigmas estabelecidos (Pessoni \& Akerman, 2014; Silva, Correia, \& Lima, 2010). Embora a tecnologia permita o acesso à informação, ela por si só não consolida o processo de apropriação do conhecimento e aprendizagem (Silva et al., 2010). No contexto escolar, o conhecimento é gerado através de práticas pedagógicas, as quais, mediadas pelo professor, possibilitam a interação, observação, prática ou memorização do aprendiz. Neste contexto, a criação de um histórico de atividades, juntamente com a inserção de observações sobre a experiência, torna-se um instrumento no aprimoramento da qualidade da prática docente (Cunha, 2009).

Existem ferramentas que permitem aos professores compartilharem suas experiências pedagógicas e material didático. Dois exemplos de ambiente web disponíveis em língua portuguesa com esta finalidade são a Plataforma Paulo Freire (Brasil. Ministério da Educação, 2009) e Gente Que Educa (Fundação Victor Civita, 2015). Porém, ainda existe um grau de resistência por parte dos professores em sua utilização, sendo um dos principais motivos 
a falta de familiaridade com a ferramenta (Canabarro \& Basso, 2013; Silva et al., 2010). Portanto, se o utilizador da mídia tiver o conhecimento necessário sobre seu funcionamento, seu uso poderá ser estimulado e aplicado no compartilhamento das experiências pedagógicas (Canabarro \& Basso, 2013; Silva et al., 2010). Deste modo, a utilização de mídias sociais no ambiente escolar pode apresentar maior aceitação como ferramenta com fins pedagógicos (Canabarro \& Basso, 2013). Ressalta-se que há diferenças conceituais entre redes sociais e mídias sociais. As redes sociais são estruturas informais que articulam indivíduos que passam a interagir por áreas de interesse, e que também podem desenvolver relações afetivas. Já as mídias sociais são um grupo de aplicações para Internet e que permitem a criação e troca de conteúdos (Costa \& Ferreira, 2012).

Dentre as mídias sociais disponíveis, a mais utilizada é o Facebook, segundo o ranking de visitas de sites disponibilizados pela ferramenta Alexa (Alexa, 2015). Nesta mídia social, os usuários devem efetuar um cadastro para ter acesso aos recursos disponíveis gratuitamente, que poderão ser: (a) perfil particular, (b) página para empresa ou instituição ou (c) grupo, que pode ser do tipo público, privado ou secreto. O conteúdo publicado por cada usuário pode ser visualizado, curtido, comentado e compartilhado por seus amigos através de botões. As publicações incluem fotos, postagens de mensagens, músicas e vídeos (Canabarro \& Basso, 2013).

Considerando este contexto, o objetivo deste trabalho foi utilizar o ambiente de mídia social Facebook como ferramenta de compartilhamento de experiências pedagógicas em um ambiente escolar, a fim de promover uma reflexão sobre o tema.

\section{PROCEDIMENTOS METODOLÓGICOS E RESULTADOS}

O ambiente de pesquisa no qual ocorreu a análise da utilização de grupos no Facebook como ferramenta de compartilhamento de experiências pedagógicas foi uma escola pública de educação infantil no meio urbano do município de Vacaria, no estado do Rio Grande do Sul. A escola apresenta como entidade mantenedora a Prefeitura Municipal de Vacaria e a Secretaria Municipal de Educação (SMED). Até o final do primeiro semestre de 2015, a equipe da escola era formada por uma diretora, uma vice-diretora, uma supervisora, oito professoras, vinte e uma funcionárias, três monitoras e cento e trinta alunos de 0 a 4 anos de idade.

Em relação às técnicas e procedimentos metodológicos, este trabalho caracteriza-se como pesquisa de natureza qualitativa e de nível exploratório, já que esta é aplicada quando o objetivo é compreender, explorar ou descrever acontecimentos e contextos, nos quais estão simultaneamente envolvidos diversos fatores. A estratégia do estudo foi a pesquisa-ação com entrevistas, documentação, observação e análise dos participantes envolvidos com a comunidade escolar e, consequentemente, com o processo de ensino-aprendizagem (Bastos \& Keller, 2012).

Incialmente, a equipe diretiva foi ouvida a fim de se estabelecer os objetivos do projeto, o qual envolveu a criação de dois mecanismos: (a) a página da escola, como instrumento de informação e atualização para os pais e a comunidade sobre os acontecimentos da escola, como, por exemplo, a programação do ano letivo e realização de eventos e, (b) grupo secreto, para tratar de assuntos relacionados a gestão da escola, como reuniões, programação de eventos, ideias e incentivos, sendo este disponível apenas para a comunidade interna da escola. Após a definição inicial, o ambiente do Facebook foi configurado e a página disponibilizada no seguinte endereço de internet: https://www.facebook.com/emeiprofjoaoalbertopaimborges (Figura 1).

A página foi apresentada para os integrantes da comunidade interna da escola, os quais participaram de um treinamento sobre as suas formas de utilização. Neste momento, foi possível aos participantes emitirem suas opiniões e esclarecerem possíveis dúvidas. Tanto a criação destes recursos quanto o treinamento dos funcionários foram realizados por uma das professoras da escola com formação de nível superior em Sistemas de Informação.

A utilização do recurso ocorreu no segundo semestre de 2014 e primeiro semestre de 2015. Após doze meses de utilização, foram realizadas 31 postagens na página da Escola, todas sob a responsabilidade da equipe diretiva, a fim de assegurar a integridade das informações compartilhadas e a proteção aos direitos das crianças. Um exemplo da interação proporcionada pela página apresentado na Figura 1. Já no grupo secreto (Figuras 2.a e .b), foram realizadas 26 postagens, inseridas tanto por professores quanto por funcionários. As postagens do grupo secreto incluíram planos de aula, mostra de trabalhos, ideias de atividades, entre outros assuntos. Todas as postagens receberam "Curtidas" e comentários dos outros integrantes do grupo.

Após esta experiência, os participantes emitiram seus relatos:

Relato 1: [...] A página e o grupo secreto tornam mais fácil o acesso do grupo e a integração entre funcionários e a comunicação entre toda a equipe escolar. [...] é muito importante para a escola e funcionários para divulgação de fotos que relatam a rotina e os trabalhos realizados, como meio de comunicação do que realmente acontece, valorizando o trabalho de todos os funcionários [...].

Relato 2: Apesar de ter bastante dificuldade quanto ao uso das tecnologias, sei que é muito importante tanto na minha vida pessoal e profissional [...]. 


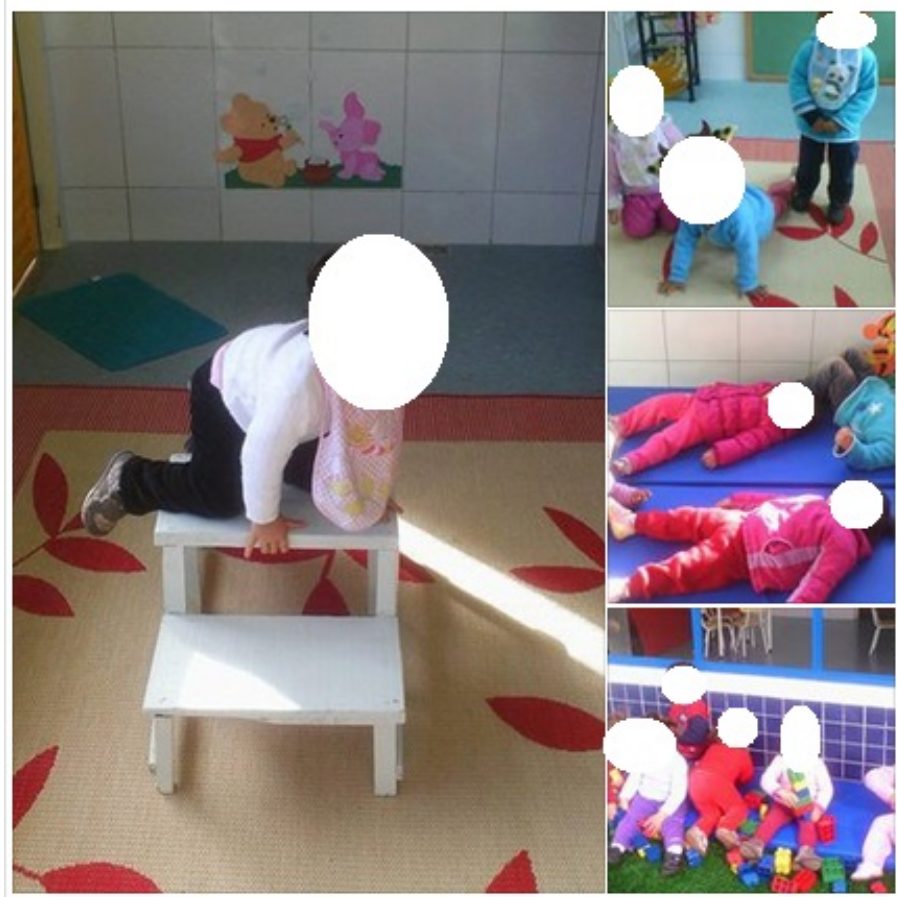

Figura 1. Exemplo de postagem na página da escola. Fonte: as autoras.

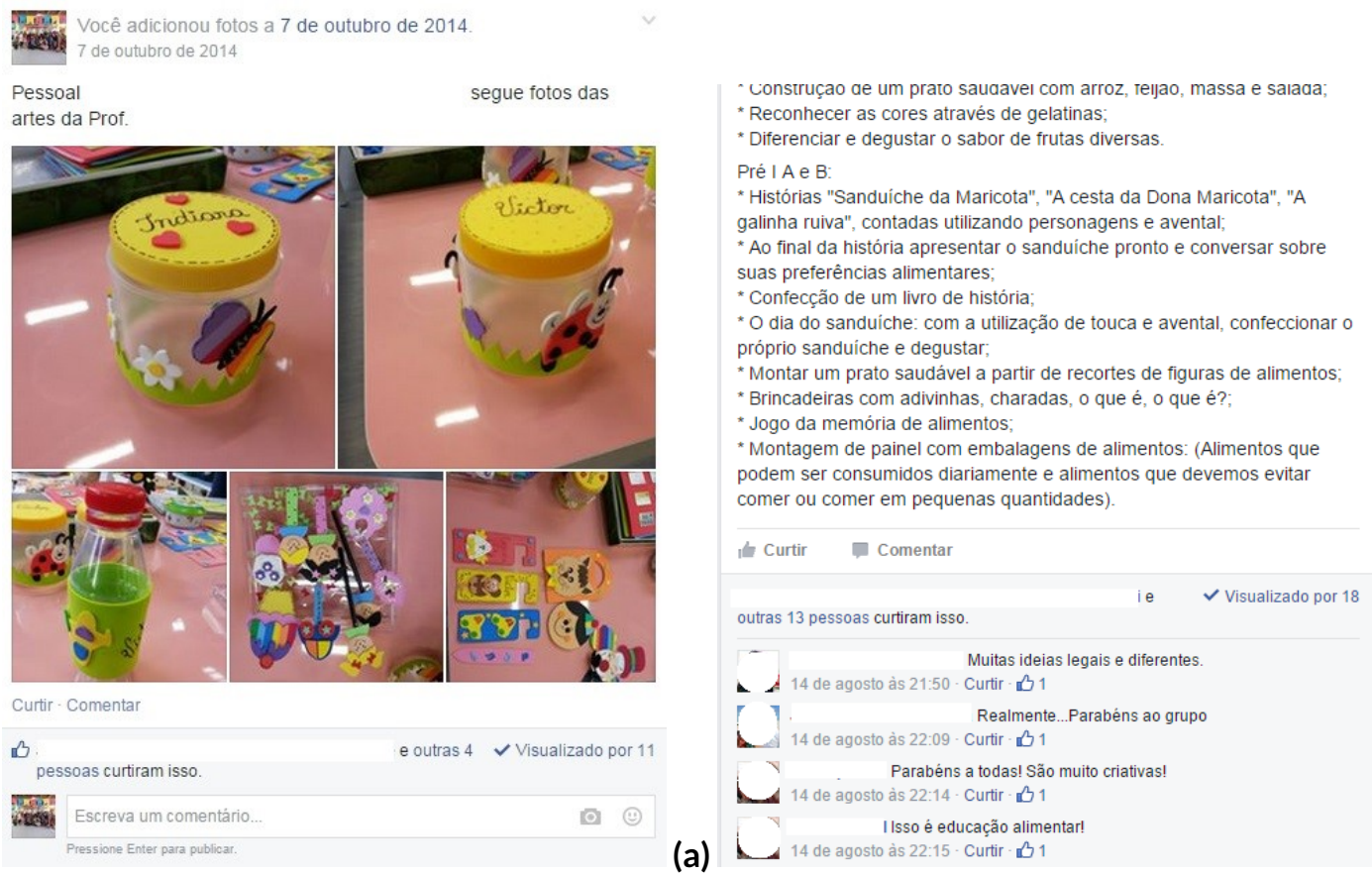

(b)

Figura 2. (a) Exemplo de postagem no grupo secreto. (b) Exemplo de postagem no grupo secreto. Fonte: as autoras.

Relato 3: O uso do Facebook (C) pela escola é uma ferramenta moderna e completa, onde cria um laço entre a escola e os pais de alunos, [...] mantém os familiares informados sobre o que está acontecendo.

Considerando que, tanto o aprimoramento da prática docente quanto o processo de formação de professores, 
são influenciados pela participação, interação, troca de experiências e cooperação, a presente experiência exemplifica o potencial de utilização de uma mídia social como ferramenta de apoio pedagógico no contexto escolar. Neste particular, Barcelos, Passerino, e Behar (2011) consideram a utilização das mídias socais digitais ainda incipiente como ferramenta pedagógica.

A utilização das redes sociais como ferramenta colaborativa e inovadora do processo de ensino-aprendizagem já vem sendo discutido por diversos autores. Costa e Ferreira (2012) apresentam diversos exemplos da utilização de mídias sociais como ferramenta pedagógica na educação básica. Os autores apresentam experiências e afirmam que as mídias sociais, como o Twitter e Facebook, possibilitam diversas oportunidades para a criação de um ambiente de aprendizagem cooperativo e colaborativo. Por se tratarem de ferramentas envolventes e fazerem parte do cotidiano, promovem a integração, comunicação, compartilhamento e colaboração entre professor e aluno. Já no âmbito da formação de professores, Barcelos et al. (2011) descrevem o projeto de formação de professores denominada T-PROIM (Tecnologias na Prática docente de pROfessores Iniciantes de Matemática). Segundo os autores, o objetivo desta proposta de formação foi contribuir para que os professores expressem suas ideias, necessidades e experiências de modo a se tornarem autores de recursos pedagógicos e construtores de práticas docentes inovadoras. Barcelos et al. (2011) afirmam que foi possível observar (a partir de questionamento aos participantes), que os recursos das redes sociais são fáceis de usar e atuam como meio de interação entre professor e aluno e entre os próprios alunos. Além disso, os autores concluem que a possibilidade de compartilhar informações cria um espaço menos formal para contexto educacional, o qual pode servir como motivação para as atividades formais.

A experiência descrita neste trabalho e em trabalhos relacionados ao tema mostram que há um movimento de discussão e reflexão sobre o tema. As tecnologias digitais oferecem possibilidades e oportunidades como ferramentas facilitadoras e inovadoras no processo ensino-aprendizagem, uma vez que estimulam o envolvimento do aluno de forma autônoma na construção do seu conhecimento. As experiências de uso das mídias sociais no âmbito da educação mostram-se relevantes, uma vez que promovem a interação entre os participantes de um grupo, sendo este um dos elementos que favorecem a internalização do conhecimento (Pessoni \& Akerman, 2014; Tomaél, Alcará, \& Di Chiara, 2005).

\section{CONCLUSÕES}

O presente trabalho apresentou uma experiência de utilização da mídia social Facebook para compartilhamento de experiências pedagógicas, a qual foi bem aceita pela comunidade escolar. A utilização do Facebook possibilitou vantagens como: (a) divulgação da rotina dos alunos da escola, (b) acompanhamento da comunidade sobre eventos no cotidiano, (c) elaboração de ideias, planos e eventos pelos funcionários da escola. Além disso, por meio da mídia social, foi possível estabelecer a criação de acervo do histórico da instituição, possibilitando a fácil utilização e disponibilidade de acesso ao material.

A implementação apresentada neste trabalho baseou-se no fato de que as relações sociais possibilitam o compartilhamento de informação. Através do uso da informação, o conhecimento é modificado, expandido, fortalecido, por meio da cooperação dos integrantes, o que proporciona aprendizado e inovação (Tomaél et al., 2005). A mídia social, por ser de fácil utilização, facilita o compartilhamento de atividades, e experiências, além de mostrar a evolução dos alunos para os demais membros da comunidade escolar. Deste modo o processo de ensino-aprendizagem pode ser aprimorado, o que contribui para os avanços na área da educação e consolidação das ferramentas tecnológicas como instrumento pedagógico.

A utilização do Facebook como ferramenta de compartilhamento do conhecimento não se limitou ao período de doze meses utilizado para a análise da experiência descrita neste artigo. A página continua sendo empregada como mecanismo de compartilhamento de informações pelos integrantes da comunidade escolar. Futuramente, pretende-se criar um acervo interno de atividades pedagógicas criadas e aplicadas pela comunidade escolar. 


\section{REFERÊNCIAS}

Alexa. (2015). Actionable analytics for the web. Recuperado em 8 fev. 2015, de http://www.alexa.com/

Barcelos, G. T., Passerino, L. M., \& Behar, P. A. (2011). Redes sociais na internet: Ambiente pessoal de aprendizagem na formação de professores iniciantes de matemática. Revista Novas Tecnologias na Educação, 9(1), 1-10. Recuperado de http://seer.ufrgs.br/renote/article/view/21902

Bastos, C. L., \& Keller, V. (2012). Aprendendo a aprender: introdução à metodologia científica (24a. ed.). Petrópolis: Vozes.

Brasil. Ministério da Educação. (2009). Plataforma paulo freire. Recuperado em 17 fev. 2015, de http://freire.capes.gov .br/index/principal/

Canabarro, M. M., \& Basso, L. O. (2013, 07). Os professores e as redes sociais: É possível utilizar o facebook para além do "curtir"? Revista Novas Tecnologias na Educação, 11(1). Recuperado de http://seer.ufrgs.br/index.php/renote/article/ view/41625

Costa, A. M. S. N., \& Ferreira, A. L. A. (2012). Novas possibilidades metodológicas para o ensino-aprendizagem mediados pelas redes sociais twitter e facebook. REnCiMa, 3(2), 136147. Recuperado de http://revistapos.cruzeirodosul.edu.br/ index.php/rencima/article/view/494

Cunha, M. C. (2009). Gestão educacional nos municípios: entraves e perspectivas. Salvador: EDUFBA.

Fundação Victor Civita. (2015). Gente que educa. Recuperado em 17 fev. 2015, de http://gentequeeduca.org.br/

Pessoni, A., \& Akerman, M. (2014, 06). O uso das mídias sociais para fins de ensino e aprendizagem: estado da arte das pesquisas do tipo survey. Educação, Cultura e Comunicação, 5(10), 29-42. Recuperado de http://publicacoes.fatea.br/ index.php/eccom/article/view/1111

Silva, A. K. A., Correia, A. E. G. C., \& Lima, I. F. (2010, jan./jun.). O conhecimento e as tecnologias na sociedade da informação. Revista Interamericana de Bibliotecología, 33(1), 213-239. Recuperado de http://www.scielo.org.co/pdf/rib/ v33n1/v33n1a09.pdf

Tomaél, M. I., Alcará, A. R., \& Di Chiara, I. G. (2005, maio/ago.). Das redes sociais à inovação. Ciência da Informação, 34(2), 93-104. doi: 10.1590/S0100-19652005000200010

Como citar este shortpaper (APA):

Marin Bernardi, P. \& de Avila e Silva, S. (2015). O uso do Facebook como ferramenta para o compartilhamento de atividades pedagógicas: uma experiência em uma escola pública de educação infantil. AtoZ: novas práticas em informação e conhecimento, 4(2), 108 - 112. Recuperado de: http://dx.doi.org/10.5380/atoz.v4i2.43496 